\title{
Like an open book? Accessibility of e-book content for academic study in a diverse student population
}

\author{
Laura Muir, Thomas Veale, Anne Nichol
}

\begin{abstract}
This paper reviews previous research on e-books and the information seeking behaviour of scholars. It presents the initial findings from an in-depth study of the behaviour and experiences of seven students (including students with dyslexia and visual impairment) using e-books for their academic coursework assignments and highlights the information accessibility issues they encountered. It discusses the need to develop a new model of e-book content delivery and proposes a framework for the evaluation of academic e-books from a commercial or 'business' perspective.
\end{abstract}

\section{Introduction}

On the 22nd January 2003, the Secretary of State for Education and Skills, Charles Clarke, announced publication of the White Paper "The Future of Higher Education", to encourage "wider participation" and "meet the needs of a more diverse student body". The changing student population includes "more older part-time students and larger numbers from non-traditional backgrounds" (Russell, 2008). This includes disabled students and students accessing learning materials remotely in courses designed for part-time and distance learning. For example, six percent of students enrolling in Scottish Higher Education Institutions declared a disability in 2006-07 and there was an increase of 5\% in distance learners from the previous academic year (Scottish Executive, 2008).

The increasing use of electronic learning materials delivered through Managed/Virtual Learning Environments by on- and off-campus learners and the

\section{Authors}

Dr Laura Muir is a Senior Lecturer in the Department of Information Management of Aberdeen Business School at Robert Gordon University, Aberdeen.

Thomas Veale was an MSc Information and Library Studies student in 2007/8 at Robert Gordon University, Aberdeen during part of the research project.

Anne Nichol is a Librarian and Faculty Liaison Advisor in the Georgina Scott Sutherland library of Robert Gordon University, Aberdeen.

Email: 1.muir@rgu.ac.uk 
legal obligations, under the Disability Discrimination Act (DDA) (Disability Discrimination Act, 2005), of educational establishments to provide equal access to a diverse student population mean that universities must ensure usability and accessibility of electronic resources provided by university libraries for all students. This includes accessible provision and use of e-books for academic study.

According to Carden (2008), an e-book may be regarded as an electronic 'picture' of a printed book, a viewable resource in an online repository, reflowable narrative text, a searchable browsable database of discrete factual components for reference or as a learning object with a toolkit for searching, highlighting and annotating its content. An e-book may be delivered to the user on a dedicated ebook reader or accessed through a library catalogue or on the WWW. In the academic context, e-books are typically accessed through the university library catalogue. The e-book delivery format tends to be similar to that of a printed book for reading one page at a time and one book at a time.

Printed books may be evaluated in terms of their 'readability', layout, availability and portability. E-books may be evaluated in the same way and also in terms of their software features and functionality. However, it is easy to focus too heavily on e-book devices, formats and features and to forget about the nature of the content that they deliver (including data, explanation, instruction, account, argument and narrative), how it is accessed and read, and the needs of the reader of the e-book.

E-books are seen as a means of increasing multi-user access to published material and offer great potential for meeting the needs of a wide range of users accessing library resources remotely (Snowhill, 2001). However, despite the potential benefits to users and libraries, the uptake of e-books has not met expectations and this has resulted in special initiatives and research to establish the issues for providers (JISC, 2008) and the barriers for users (JISC, 2003). The JISC National E-books Observatory Project (JISC, 2008a) was initiated to explore impact, observe behaviours and develop new models to stimulate the e-books market. It was driven by the demand for course texts in electronic format and conflicting concerns of publishers about lack of evidence of demand and the impact on sales of printed books. One of the key aims of that project is to evaluate the use of the e-books through deep log analysis to enable publishers, aggregators and libraries to stimulate an e-books market that has appropriate business and licensing models. An initial online survey (CIBER, 2008) gathered information on awareness, perceptions and attitudes to e-books as a benchmark for further studies. Deep Log Analysis (DLA) of raw server logs (of user access, navigation and activity) together with user and institutional profiles and interview data has explored patterns of behaviour in the use of e-books in a large-scale study.

This paper provides an in-depth view of scholarly e-books from a student-centred perspective. Rather than looking at general patterns of behaviour, it examines the student's journey through an e-book in the context of their study goals and records their behaviour and experiences as individual case studies of e-book interaction. It explores the attitudes and experiences of students on e-book use for their studies, comparing their views before and after a recorded e-book session and examining 
usability, accessibility and the processes involved in using e-books. The accessibility and usability of e-books is of particular interest to publishers, aggregators and users. Our research aims to evaluate e-books from a commercial or 'business' perspective to inform the design and delivery of e-book content in the future.

\section{Usage and attitudes to e-books}

Research on e-books has generally focused on usage (for example, Levine-Clark, 2006) and attitudes to use. Surveys of students' attitudes to the use of e-books found that 24/7 availability, ease of storage and full-text search facility were drivers for use (Chu, 2003). Difficulty in reading/browsing/annotating content, the need for special equipment, no sense of ownership (when frequent use is required over an academic year) and preference for print were found to be the main perceived barriers to use (Rowlands et al., 2007; Tenopir and Rowlands, 2007). Researchers concluded that e-book content which is suitable for quick reference is used more widely (Chu, 2003; Williams and Rowlands, 2007, 20) and that the subject and content of e-books influences how heavily the e-book will be used (Chu, 2003, 41). Prior experience of using e-books has also been found to positively influence acceptability and use of e-books for reference tasks. Specific issues for use were found to be navigation time relative to the time spent viewing content, perceived barriers to access which dissuade use of e-books and the need for simplicity and standardised, easy-to-use interfaces (CIBER, 2008). In a study of Electronic Books ON-screen Interface (the EBONI project) by Wilson, Landoni and Gibb (2002), a set of best practice guidelines was produced for the publication of electronic textbooks, reflecting the usability requirements of the UK higher education community. The main findings of the EBONI study were the need for adherence to the printed book model and presentation adjustments to facilitate ease of on-screen reading.

However, our research challenges this recommendation and argues that it is the adherence to the printed book model that limits the use of academic e-books. We argue that e-book content must be re-designed to meet the scholarly information seeking needs of the user.

\section{Understanding scholarly information seeking behaviour}

Information seeking behaviour is exhibited during "the purposive seeking for information", which is the "consequence of a need to satisfy some goal" or "a process in which humans purposefully engage, in order to change their state of knowledge" (Marchionini, 1995). It is important to note the importance of the 'goal': information seeking behaviour cannot be explored if there is no clear user goal or genuine need for the information.

One aspect of information seeking activity is the way in which the user interacts with the e-book and the information obtained from it. In addition, variables such as motivation, attitude and experience influence the decisions users make while seeking and using information. Therefore, in a study of information seeking behaviour, it is important to capture the users' physical interaction with the information environment and the thought processes, knowledge structures, 
attitudes and affective influences which determine how the information is discovered and used.

Researchers have called for information and library research to move towards "monitoring the actual online seeking behaviour of their users" (CIBER, 2008, 9). Rowlands (2007) argued that "no one is watching the users". He concluded that there is generally a lack of research in user evaluation of expensive online resources. Significant differences in perceptions and views between researchers and library service providers are identified in a report on researchers' use of academic libraries and their services (RIN, 2007). This demonstrates the need for greater understanding of how users interact with and use library services in general and e-books in particular. In a recent report, commissioned by the Strategic Content Alliance (SCA) ${ }^{*}$ on Audience Analysis and Modelling (SCA, 2008), personalisation and the importance of usability testing for user engagement and feedback are identified as key themes for the future development of library resources.

Our research was specifically designed to explore the behaviour and experience of students using e-books for their academic study. This paper explores the information accessibility issues arising from this work.

\section{Methodology}

A mainly qualitative approach to understanding the multidimensional nature of scholarly information seeking (physical, cognitive, affective and socio-cultural) during e-book use was adopted in our user-centred research which aimed to understand not only the characteristics of behaviour but also why users behave in certain ways. The general research approach was qualitative at the ontological level (i.e. a relativist approach) and at the epistemological level (i.e. an interpretivist $^{\dagger}$ and subjectivist view). It was at higher levels that the research combined qualitative and quantitative elements. At the methodological level the approach used exploratory and descriptive (qualitative) methods to capture views and experiences and confirmatory (quantitative) methods to capture the behavioural mechanisms of participants. At the axiological level the approach was qualitative (to establish relevance) and quantitative (to enhance rigour and provide supporting evidence).

Wilson and Landoni (2001) recognised the link with Human Computer Interaction research in their methodology for evaluating e-books, which included subjective feedback obtained by questionnaire, covert behaviour observation and interviews. This general approach was adopted in our research to gather data for the creation of individual user case studies of interactions with e-books.

"The SCA comprises the JISC, BL, BBC, NHS, Becta, MLA and EPSRC.

${ }^{\dagger}$ Interpretivism is an approach where reality is subjective and constructed by human actors in contrast with positivism where facts and values are distinct. 


\subsection{Methodological approach}

Case study research is an in-depth study where the unit of analysis is an individual, group, organisation, event or phenomenon related to the research questions. It is well suited to empirically investigating user behaviour and issues for individuals and groups and for investigating the interaction between the context and systems or services. In this approach, phenomena under investigation are not isolated from their context and it is precisely for this reason that it is of value. By not separating the components (i.e. the e-book platforms and content) from related matters (the educational context and goal) a holistic examination was possible.

In this research, the primary unit of analysis was the individual e-book user (student) but it is envisaged that as the study develops to include more student participants, further case studies will be created based on groups of students (according to student profile categories or consistent behaviour patterns if they emerge). This will enable the creation of usage scenarios that typify specific issues which characterise user behaviours. However, the aim of our research is not to over-generalise the findings but to embrace the 'outliers' in an inclusive study aimed at achieving universal usability and accessibility of e-books of the future.

\subsection{Participants}

Seven postgraduate students (from Robert Gordon University, Aberdeen) volunteered to take part in the research and they are described in Table 1.

\begin{tabular}{|l|l|}
\hline ID & Student \\
\hline S1 & $\begin{array}{l}\text { Female, Dyslexic (Meares-Irlen Syndrome, a severe form of dyslexia } \\
\text { due to pattern sensitivity, wears tinted glasses), on-campus access. }\end{array}$ \\
\hline S2 & Female, Dyslexic, on-campus access. \\
\hline S3 & Female, on-campus access. \\
\hline S4 & Female, on-campus access. \\
\hline S5 & Female, on-campus access. \\
\hline S6 & Male, off-campus access (Distance Learning student). \\
\hline S7 & Male, Blind from birth, off-campus access. \\
\hline
\end{tabular}

\section{Table 1: Student participants}

None of the participants was an experienced user of e-books prior to the study. Student 7 is an expert user of assistive technology software (for text-to-speech). The volunteers who took part in the research all expressed an interest in e-books but stated a preference for the printed format before they participated in the research (apart from Student 7). Their willingness to work on the e-book task contributed greatly to the research. By participating, they also had an opportunity to assess how e-books might play a greater role in their studies in future. 


\subsection{The e-book task}

The participants were given a task which was designed to make their interaction with e-books realistic, practical and student-centred. The task was to use e-book content of their choice for their own information needs for a current coursework assignment. This required pre-task preparation by the students to identify the information requirements for a specific coursework assignment. The e-books read by the six students who gained access to one or more e-books during the task are detailed in Table 2. Student 7 was not able to access the e-book of his choice and is not included in the table.

\begin{tabular}{|l|l|l|l|}
\hline ID & E-Book & Source & Read by \\
\hline EB 1 & $\begin{array}{l}\text { Creswell, J.W. (1997) Qualitative } \\
\text { inquiry and research design: choosing } \\
\text { among five traditions.1st ed. London: } \\
\text { Sage. }\end{array}$ & $\begin{array}{l}\text { NetLibrary } \\
\text { (NL) }\end{array}$ & S1, S3, S5 \\
\hline EB 2 & $\begin{array}{l}\text { Lee-Davies, L. (2007) Developing work } \\
\text { and study skills. London: Thomson } \\
\text { learning. }\end{array}$ & $\begin{array}{l}\text { Biz/ed } \\
\text { Premier } \\
\text { (BE) }\end{array}$ & S2 \\
\hline EB 3 & $\begin{array}{l}\text { Mauch, J.E., Park, N. (2003) Guide to } \\
\text { the successful thesis and dissertation: a } \\
\text { handbook for students and faculty. 5th } \\
\text { ed. New York: M. Dekker. }\end{array}$ & $\begin{array}{l}\text { MyiLibrary } \\
\text { (ML) }\end{array}$ & S4 \\
\hline EB 4 & $\begin{array}{l}\text { Budd, J. (1998) The academic library: } \\
\text { its context, its purpose and its operation. } \\
\text { Englewood CO.: Libraries Unlimited. }\end{array}$ & $\begin{array}{l}\text { NetLibrary } \\
\text { (NL) }\end{array}$ & S4 \\
\hline EB 5 & $\begin{array}{l}\text { Featherstone, M., Hepworth, M., and } \\
\text { Turner, B.S., eds. (1991) The body: } \\
\text { social process and cultural theory. } \\
\text { London: Sage. }\end{array}$ & $\begin{array}{l}\text { NetLibrary } \\
\text { (NL) }\end{array}$ & S6 \\
\hline
\end{tabular}

Table 2: E-Books (EB1-EB5) accessed and read by participating students (S1-S6)

\subsection{Data collection methods}

Data were obtained from a pre-task questionnaire, a recording of the e-book task session and a post-task interview.

The pre-task questionnaire obtained data about the students, their background, information needs and previous experience and attitudes to e-books. It invited the participants to examine e-books for their studies and use the content in relation to their own information needs. Training on accessing e-books from the university library and use of e-book features (for example, using the 'Table of Contents', searching electronic material, note-taking) was available to all the students taking part before the e-book task session and was provided on request to one of the students (S6).

The e-book sessions with individual participants were observed by the researcher and recorded with usability software (TechSmith Morae) and a Webcam installed on the user's computer (for S1-5 and S7. S6 recorded his session remotely). The 
participants were instructed to find access and use an e-book for their assignment and to think aloud during the session as much as possible. The software facilitated capture of the participants' interaction with the e-books (including screen display, mouse clicks, navigation, key strokes and text entry) during the recorded session. The hardware (Webcam) captured video of the users' facial expressions and an audio recording of their 'think aloud' processes during the task. The software also enabled the recordings to be integrated and rendered as a single video clip for each participant. An example of screen-shots from a video clip produced in this way (but not from the research in this paper for reasons of participant data protection) is given in Figure 1.

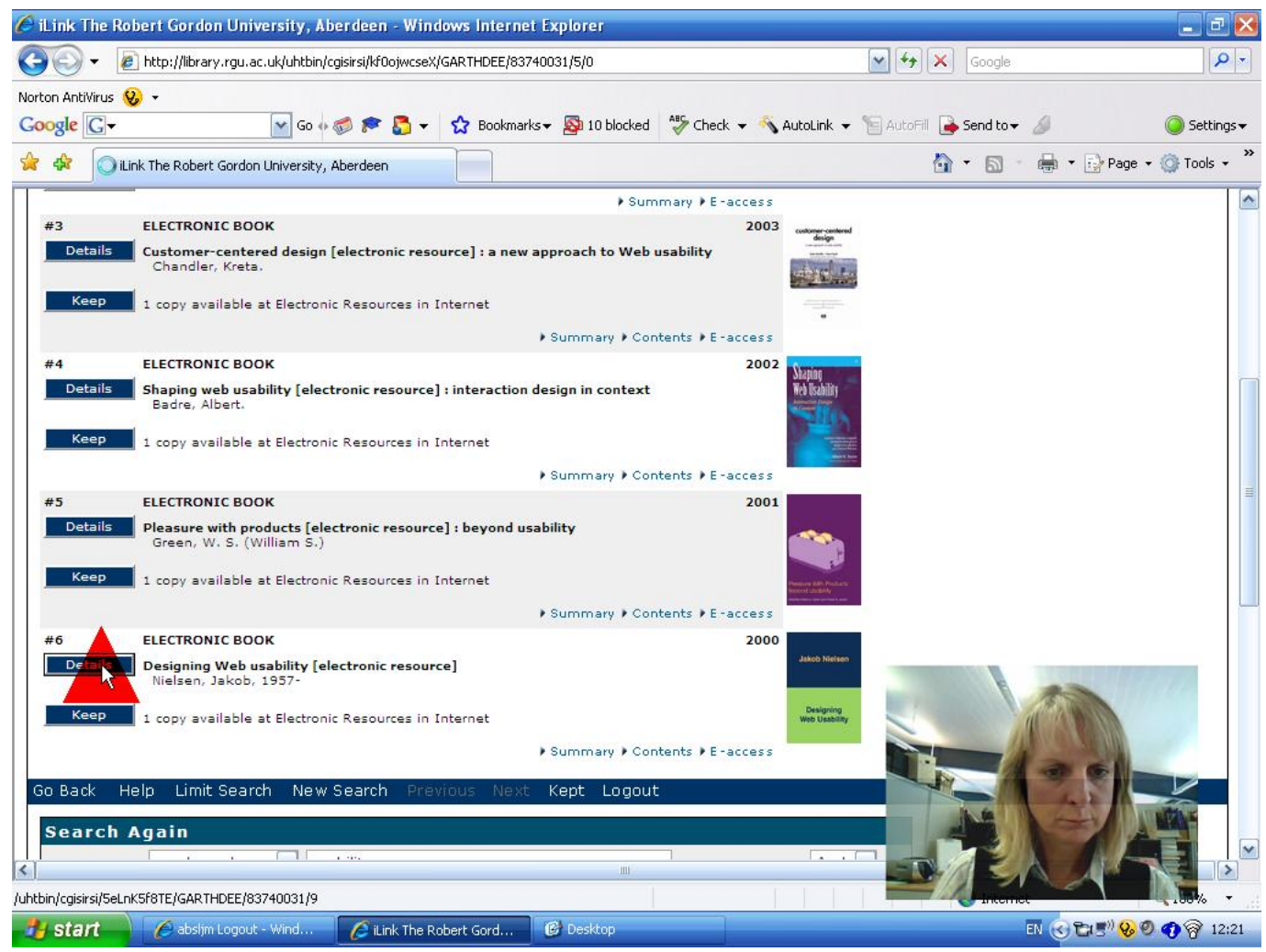




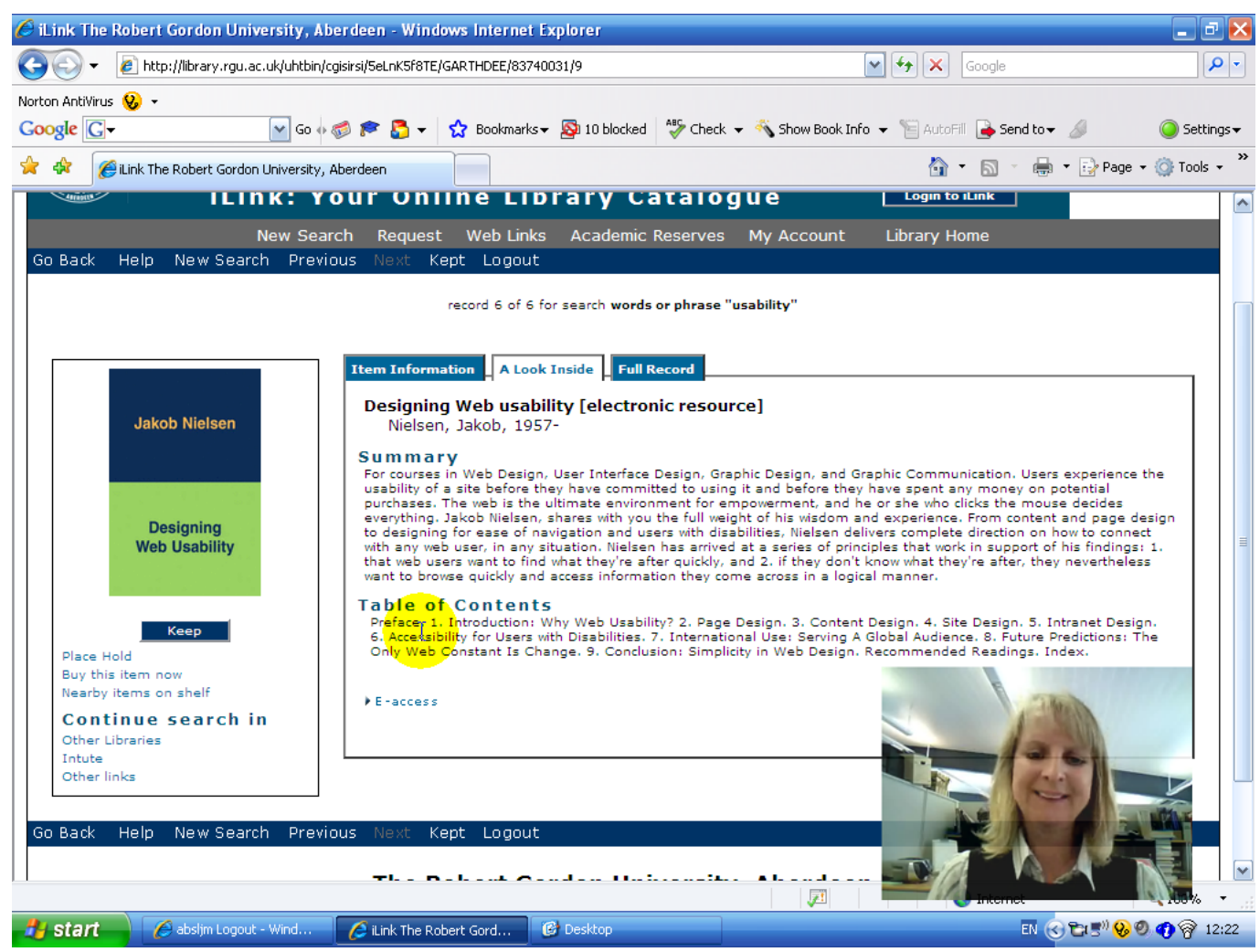

Figure 1: Two screen shots from a recorded video clip (a mouse click is indicated by the red triangle in the top image, the position of the mouse is highlighted by the yellow circle in the lower image and the image of the user is displayed in the bottom right corner of the images)

In addition to the recordings of the user during the e-book session, quantitative data (e.g. number of mouse clicks and time on tasks and subtasks) from each session were generated by the software package for further analysis.

Immediately after the recorded session, a semi-structured interview was conducted with individual participants. The interview was designed to encourage the participant to express his/her feelings and views and describe his/her experience during the task. The researcher had the option to play back video clips from the recording to the participant to facilitate this process.

Triangulation of the quantitative and qualitative data provided a rich picture of the behaviour and experience of each student participant. The key behaviours, experiences and accessibility issues arising from these detailed cases are discussed in this paper.

\section{Results}

This paper presents the analysis of the data from the questionnaire, recorded session and interview results from the first group of seven students (S1-S7) taking part in the research. It highlights the students' experiences of initial access to the e-book and its content; how they used and would like to use e-books and what helped and hindered them in using e-books to achieve their scholarly goals. 


\subsection{Initial access}

The time spent on initial access to the chosen e-book (i.e. the time to load the ebook) ranged from 2 to 136 seconds for S1-S6 (Figure 1) and the number of user actions (e.g. scrolling, text/password entry, option selections, mouse clicks) during this time are illustrated in Figure 2.

Student 7 took so long to access the e-book (using assistive technology software for screen reading) that the time could not be adequately represented on the same chart and he gave up on the remainder of the task as a result. He expressed disappointment that "unfamiliarity with the interface and slow performance of the system" for delivering the e-book was a "barrier" to his use of this resource.

Student 4 accessed her chosen e-book from MyiLibrary almost instantly (2 seconds) and the number of user actions she executed to gain initial access to the e-book was the lowest (along with S2) in the participating group. Although the number of actions required by $\mathrm{S} 2$ to gain access to her chosen e-book in Biz/ed Premier was the same as for S4, the time taken was longer (30 seconds) due to slower performance of the system.

Of the students accessing the e-books on-campus, $\mathrm{S} 1$ took the most time to access her chosen e-book (75 seconds) in NetLibrary due to the relatively high number of user actions she performed during this time (attributed to her severe form of dyslexia). The same book was accessed by S3 and S5 but they both executed fewer than half the number of user actions of S1. The difference in time to access this e-book between S3 and S5 is attributed to the differences in the performance of the network at the time of access.

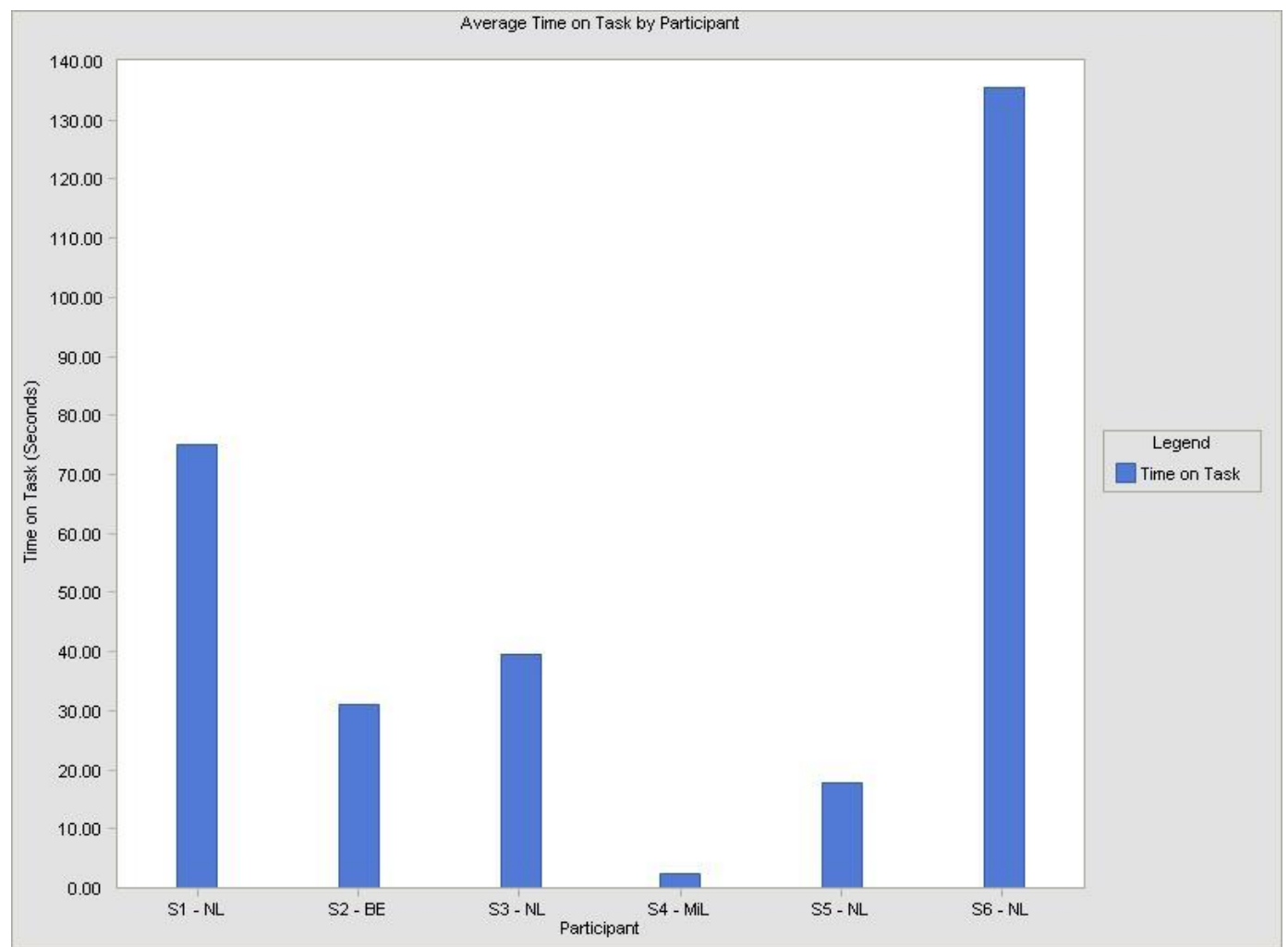

Figure 1: Time on initial access to the chosen e-book for Students 1 to 6 (S1S6) 


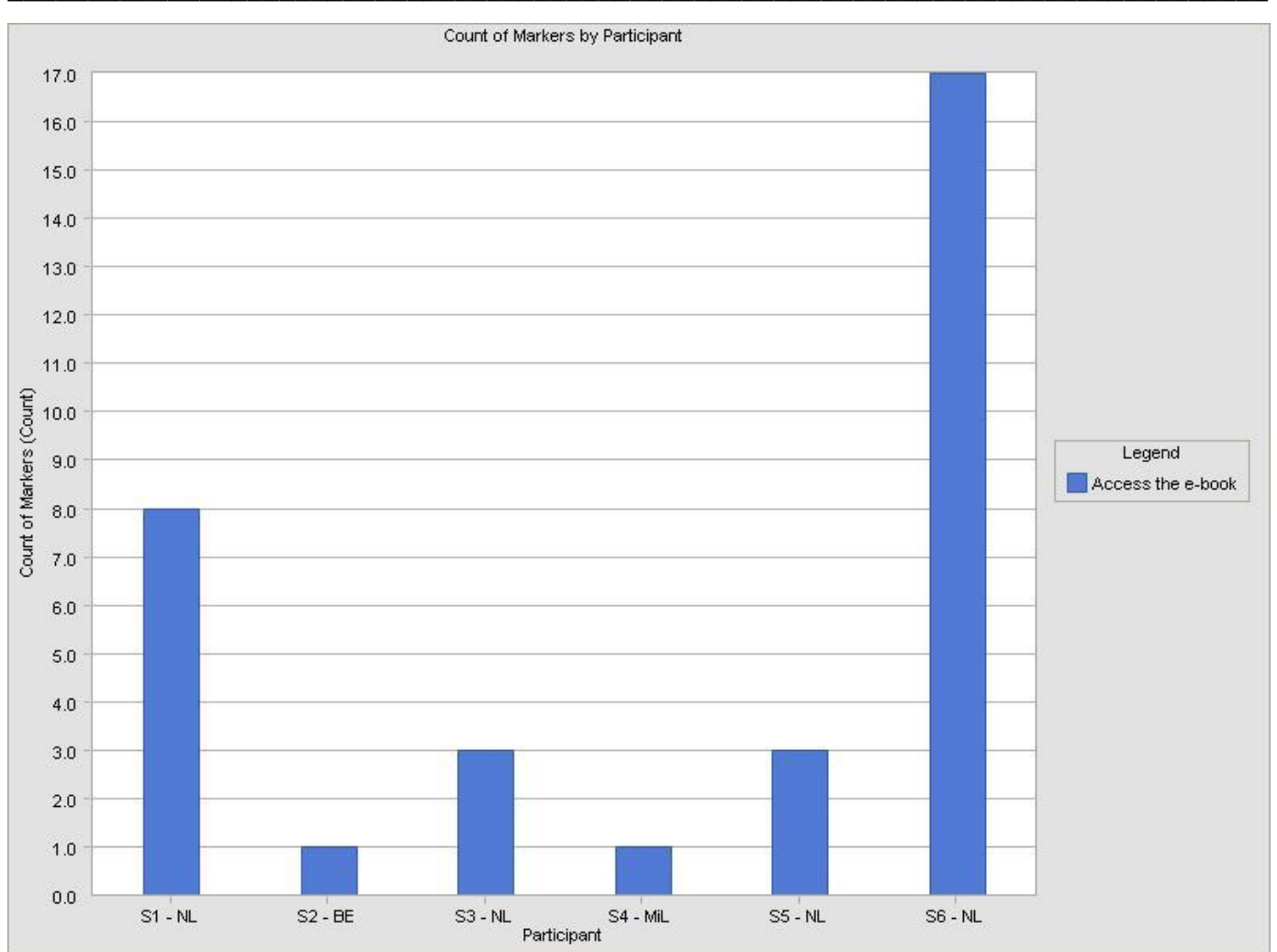

Figure 2: Number of user actions during initial access to the chosen e-book for Students 1 to 6 (S1-S6)

Student 6 gained initial access to his chosen e-book off-campus from NetLibrary in the longest time period (136 seconds) and greatest number of user actions in the participating group. Additional steps in the access process for off-campus students studying by distance learning was a key reason for this but the student felt that the number of steps in the process was too burdensome.

All of the students commented that the interface to the e-book content was not intuitive and that the user actions required to access the books were not clear. This was clearly evident in the experience of the student who is blind (S7) and the student with a severe form of dyslexia (S1), but the user experience was also considered to be unsatisfactory for off-campus access. Even those students (S4 and S5) who gained relatively quick access in fewer user actions felt that the system could be more "user-friendly".

\subsection{Accessing e-book features}

After initial access to the content of the chosen e-book, four of the students (S1, S2, S3 and S5) accessed the full features of the e-book for note taking. The time taken by the students to access the additional features is illustrated in Figure 3 and the number of user actions to gain access is represented in Figure 4. 


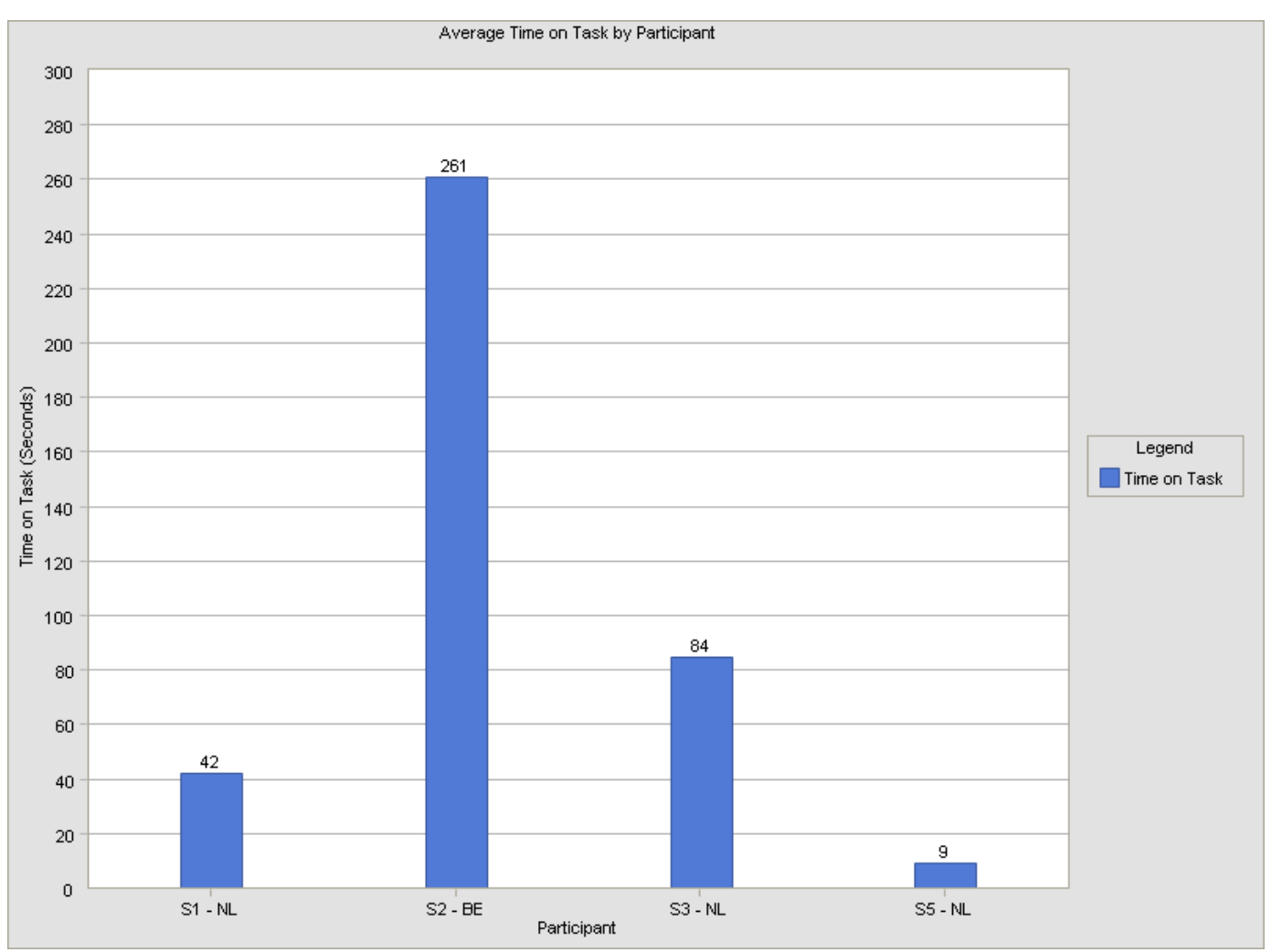

Figure 3: Time to access the full features of the chosen e-book

Figures 3 and 4 illustrate the different experiences of each of the 3 students (S1, S3 and S5) in terms of time and actions required to gain access to the note taking feature in the same e-book in NetLibrary. In this case the time varied from 9 to 84 seconds and reflected the pattern of user actions executed by the students ( 2 to 11 user actions). The additional steps to login to the system to receive these features were not clear to S1 and S3 and it was not obvious to them that full access had been achieved. For the same reasons, the experience of S2 accessing her e-book features in Biz/ed Premier was particularly time consuming (261 seconds) and labour intensive ( 25 user actions). Student 6 stated that he did not attempt to access the full features of the e-book due to the time it had taken for him to gain initial access to the e-book. 


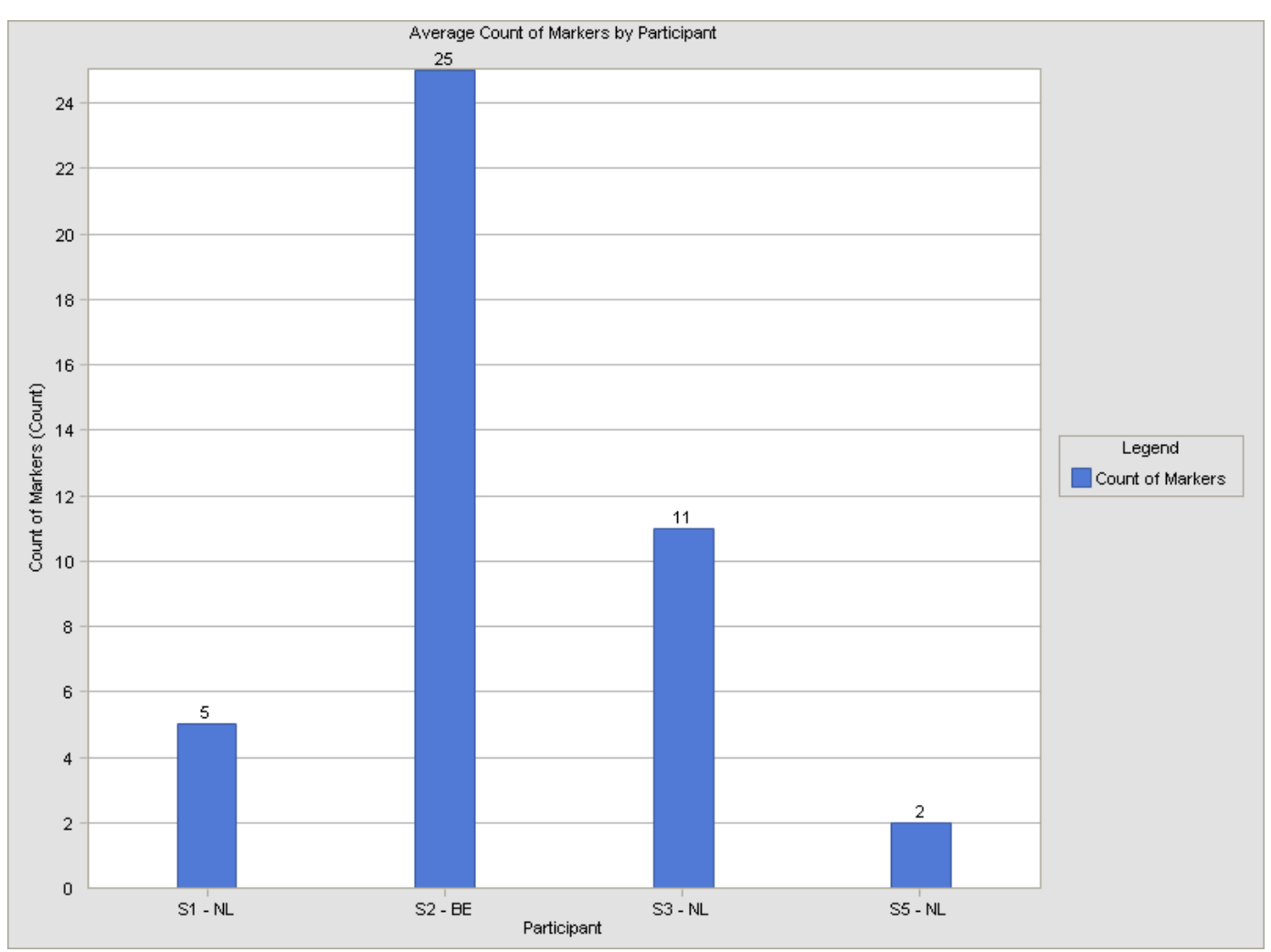

Figure 4: Number of user actions required to access the full features of the chosen e-book

\subsection{Using e-books for academic study}

Prior to undertaking the use of e-books in the task, the participants expressed a desire to use e-books as a more "convenient" way to obtain information for their coursework assignments. They all expressed the view that they would not use an e-book for a prolonged period due to the strain of reading text on a computer screen. However, they all acknowledged that they did spend a lot of time looking at computer screens for other study and leisure activities. The students also felt that patience, concentration, attention and time were required for the e-book task but they also recognised the importance of these for any type of reading activity.

After access to the e-book was achieved, the students' interactions and attempted actions with e-books were observed and recorded. The average number of mouse movements (measured in pixels) was recorded while the e-book was open and in use by Students 1-6 (Figure 5) and illustrates the relatively intense physical activity (such as mouse movements, clicks, navigation and scrolling) by Student 1 . 


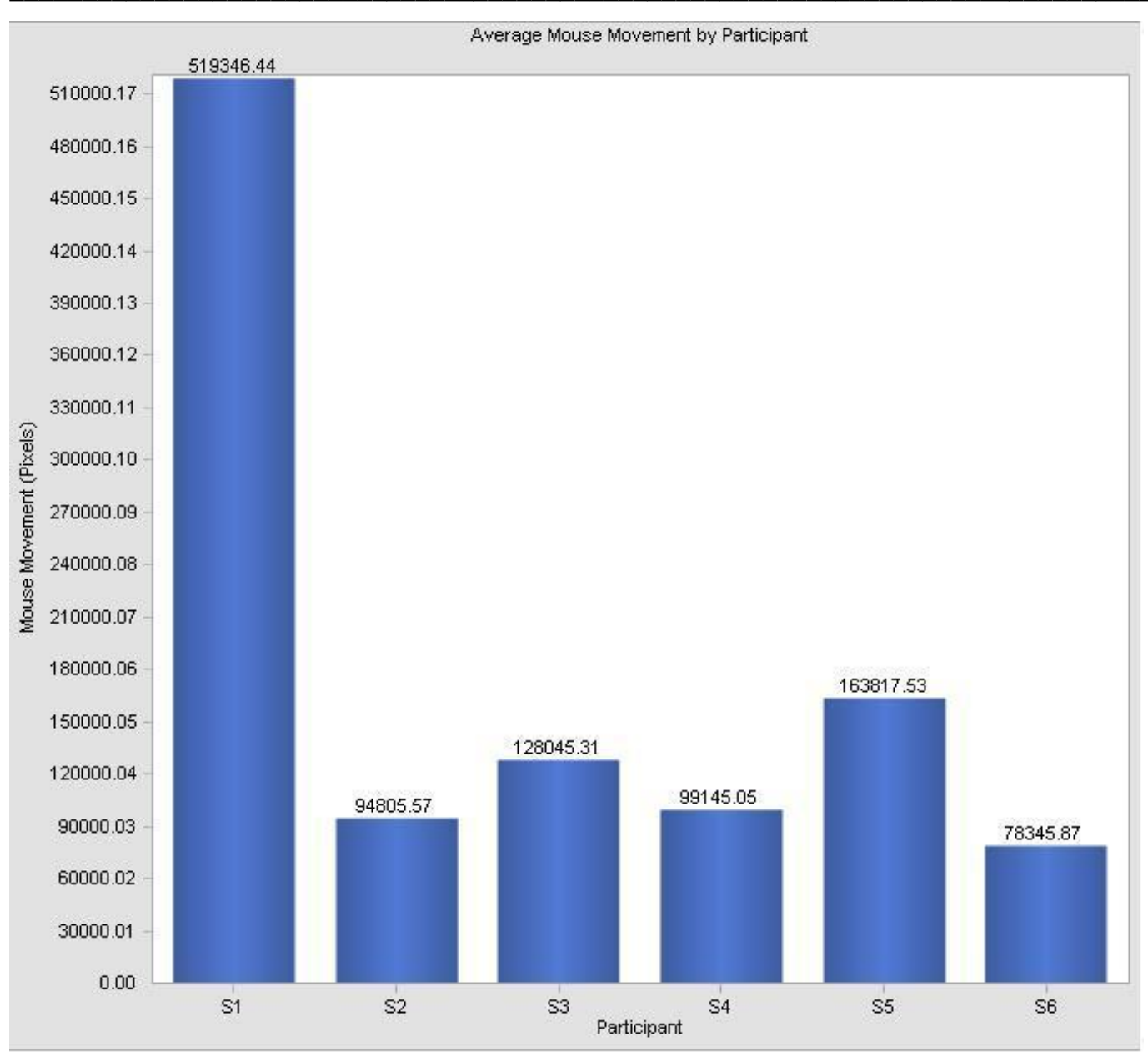

Figure 5: Average mouse movement (pixels) for each student while the ebooks were open and in use.

However, it was the actual experience of students using e-books for their study which was of most value in this research and the results are discussed in the context of the actions (highlighting, marking, annotating, searching, scanning, evaluating, navigating and reading) of the students during the task.

Highlighting text was achieved with difficulty due to the slow performance of the system resulting in repeated attempts to highlight the same piece of text. S1 attempted to highlight text 12 times and tried to copy and paste it into an MS Word document. Student 2 expected the highlighting facility to work in the same way as in MS Word, that is by clicking the highlighter tool before highlighting the text. A pop-up dialog box instructed her to click the text first. The slow responsiveness of the system resulted in her presumption that the action had no effect and so she repeated the action 5 times during the load time (50 seconds).

Bookmarking sections and paragraphs was not possible as only whole pages could be marked in this way. Student 2, had developed particular study strategies for her dyslexia and commented that she found it easier to bookmark printed material with adhesive (repositionable) paper notes. Her experience of annotation was frustrating due to the time ( 2 minutes and 15 seconds) and 11 actions to load the 
annotation box. This appeared to be due to her failed attempt to annotate bullet points (which was not permitted).

Taking notes and paraphrasing text was difficult due to access barriers and system performance issues (previously discussed in 5.2). Student 1 successfully created a list of notes in NetLibrary but her attempt to email the notes to herself failed and she did not receive them. She attempted to annotate passages of text but found that only full pages could be marked in this way (S5 also attempted this action). She was confused by the appearance of a menu when right-clicking over highlighted text as she assumed it would apply to that text (rather than the notes pane on the left as was the case). Student 2 used the note taking facility but her hand-written notes were far more extensive and useful for the scholarly task. Student 3 inadvertently started, and immediately tried to quit, the process of accessing the full features of the e-book in NetLibrary and this caused a break in reading flow of 3 minutes. Student 4 preferred to make her own written notes as she felt they were always accessible.

Full text searching was seen as a particular benefit of e-books compared to printed texts by the students. Student 1 searched for the term 'triangulation'. However, she found that the display of results was poor, even when the pane was enlarged, as the contextual information was inadequate. This resulted in additional user effort: browsing the contents in the right-hand pane to see which chapter or section the research result referred to. The search results were also found to be inadequate for the task because the hyperlink took the student to the page of the result rather than its precise location requiring the student to scroll down the page to find the appropriate section. The amount of scrolling required to navigate ebook content was generally found to increase user effort and have a negative impact on user satisfaction.

Generally, presenting information in context in the e-book was an issue that was raised by $\mathrm{S} 1$ and was also observed in the interactions of the other students. Flicking and scanning the e-book text to evaluate the content prior to reading was typically not well facilitated in the e-books. Student 3 was frustrated by the long page loading times which inhibited her ability to flick and scan through the ebook content to assess its relevancy in NetLibrary. Signposting in the text (EB2) was found to be particularly helpful to S2's evaluation and contextualisation of the content. She commented that the structure of the content described at various points in the e-book (a walk-through tour at the beginning, a section on purpose and content in the introduction, learning objectives at the start of each chapter and bullet points describing the organisation of sections) was particularly helpful.

Navigating the content of the e-book in Biz/ed premier was found to be "easy" by S2 using the Table of Contents, the control at the bottom of each page and hyperlinks in the text. However, the number of scrolling actions required and long page-loading times increased the effort required for her to use the resource effectively. The symbols used in the icons (for example, to access the 'annotation manager') were not intuitive (and difficult for her to remember) and so she relied on the alternative text produced by hovering the mouse over the symbol. This student commented on the usefulness of the always available Table of Contents and S4 was particularly emphatic in her praise for this feature (although she used 
the page navigation more frequently for sequential page reading). Student 5 suggested that page numbers should be included in the Table of Contents so that the user can assess the size of the chapters/sections. Student 1 commented on "cluttered distracting elements" in the e-book in NetLibrary making navigation difficult. Lengthy pages were found to inhibit ease of navigation, requiring more scrolling, and short pages were preferred for easier and more 'digestible' reading. Student 3 commented that the variability in the methods of navigation between different e-book providers was confusing. Interrupted reading flow and increased scrolling activity was caused by sentences and tables split across pages. Student 3 became impatient with this and skimmed over the content as a result. Student 5 experienced tables which did not fit on the screen and required scrolling after which she navigated to the next page where she found the continuation of a sentence that had started 2 pages previously (i.e. before the table). This interrupted her reading flow and understanding of the content as she had to navigate back twice, scroll down to the end of the page and then navigate forward twice to continue reading. On the fourth occurrence of this problem she did not attempt to return to the previous page and ended the session shortly afterwards. Student 6 found the lack of a scroll bar to indicate whether there was more text on a page was unhelpful. It caused him to miss content (and to have to navigate back) on two occasions and he developed the habit of scrolling to the top of every page before navigating forward. Student 6 performed 176 user actions during his reading, all in the right-hand pane (e-book text). Of these, most were scrolling actions (112) equivalent to 1.9 actions per page and 1.75 actions per minute.

Although students generally stated in the pre-task questionnaire that they would be more likely to read for quick reference, the evidence showed that they did read pages sequentially for a considerable period of time during the task. Student 4 stated that e-books are "useful for when you have specific areas to address rather than reading the whole." She read from two e-books: first in NetLibrary (until she was locked out by the provider after 15 minutes and 58 seconds) and then in MyiLibrary (41 minutes 54 seconds). She changed her opinion to a preference for e-books over printed books as a result of the session. She expressed a preference for features in MyiLibrary for easy reading such as the expandable Table of Contents in the left-hand pane and the digestible content length and navigation control at the bottom of the right-hand pane. In her second e-book of the session in MyiLibrary, S4 read the pages sequentially, using the navigation control on each page, from the cover to the end of Unit 1 in 39 minutes 15 seconds. In the pre-task questionnaire she indicated that she had not expected to read for prolonged periods. During the task she demonstrated thorough reading by going back over content on the previous page to re-read the start of a sentence before continuing. Some pages were scanned and others were read more slowly (for example, page 18 was read in 4 minutes 50 seconds). Student 5 read 51 pages sequentially in 45 minutes 4 seconds. Her thorough reading for topic understanding was demonstrated by her use of the content as the author advised. For example, when she came across a reference to an appendix in chapter 3 she navigated to it at that point in the session. The maximum reading time was by S6 who read 60 pages sequentially from one chapter of his chosen e-book in a session lasting 66 minutes and 17 seconds. 
The participants were asked if they had any recommendations for the development of e-books. Student 2 commented on the need for a new approach to e-books (although no specific format was suggested). Student 6 suggested that a standard format, simplified access and a wider range of content would improve ebook usability for academic study.

\section{Discussion}

Although the number of participants in this initial research was limited, the volume of data and depth of analysis provided a valuable insight into the behaviour and experiences of students using e-books for their academic study.

The participants were generally positive and enthusiastic about the potential of ebooks for study after completion of the task. However, they were frustrated by the barriers to their effective use as a scholarly resource.

The participants valued full-text searching and the always available Table of Contents (although the inclusion of page numbers was a recommended addition) in the e-books.

The students were dissatisfied with the complex and unfamiliar user interface, poor 'learnability' of the e-book features, lack of ease of flicking and scanning to evaluate the content of the e-book, lack of e-book and chapter reading progress information, insufficient signposting within the e-book content, lengthy pages requiring scrolling, interrupted reading flow due to content (e.g. text and tables) split over two or more pages, poor display of search results, subject index links to pages rather than passages of text (requiring scrolling to find the relevant section), slow response to actions (e.g. highlighting and note taking) and the time and number of actions required to access the e-book and the full features of the e-book (including additional login for full access). Eye strain due to reading on a PC screen was also mentioned as a barrier to very long reading sessions (particularly by the students with dyslexia). It is anticipated that wider availability of technology such as Jepsen's PixelQi low-cost and low-power 'e-paper' display screen for laptops and the Kindle E-Book Reader (IEEE Spectrum, 9 June 2009) will make screen reading easier on the eyes in the future.

One potential solution for improving the user experience of e-books is the application of a form of adaptive personalisation. The concept is to make the service adapt to the user, rather than forcing the user to adapt to the system. A report commissioned by JISC investigated personalisation of online resources (in general) for education and research based on a review of available literature and on interviews with key stakeholders (JISC, 2008b). However, the findings highlighted issues of negative perceptions of privacy and trust, inappropriate categorisation of users in personalised systems and the need for greater understanding of user requirements. One of their recommendations was that improved user experience or functionality should be explicitly linked to desired outcomes. This has been the approach in our research.

Nevertheless, evaluating e-books from a student (user) perspective is only the first step towards making e-book content usable and accessible for scholarly activity. In the quest for a model of academic e-book delivery which meets the needs of the 
user we argue that, as e-books are commercial products, it is essential to take a wider commercial or business perspective which includes the user as the customer.

The research presented in this paper is the initial stage of a research project which considers e-book production, delivery and use as a complete work system. Analysis of user requirements, without considering the processes, infrastructure and other participants (including authors, publishers and e-book aggregators) in the e-book work system would limit the commercial viability of any new approach to delivering e-books. Previous research on e-book use and usability has tended to focus on technical/functional requirements or user feedback without considering the implementation of a new solution to meet users' study needs. This has resulted in research which recommends modifications to the existing delivery model of e-books rather than a radical change. A solution which addresses user requirements but is not commercially viable is of no value. It is for this reason that our research applies Principle-Based Systems Analysis (PBSA) to the evaluation of e-books.

PBSA (Alter, 2002) is a framework for evaluating systems from a 'business' view-point rather than purely from a customer (user), technical or functional perspective. It defines a work system as having eight elements; customers (users), products and services (which the work system exists to produce), processes (system activities), participants (all who contribute to the creation, delivery and support of the system), information (used and captured in the system), technology (dedicated hardware, software and equipment), infrastructure (the supporting human, information and technical resources) and context (the organisational, competitive, technical and regulatory environment).

By considering all eight elements of the e-book work system, the solution to the problem of meeting the needs of students using e-books is addressed in the context of a viable business model for delivery.

PBSA applies seven work system principles to the eight elements of a system. The seven principles are applied to the e-book delivery system to address the business problem of delivering e-books for scholarly activity:

1. Please the customers (users) - to meet the needs of the scholar and to provide a pleasing experience in terms of product $\&$ service delivery.

2. Perform work efficiently - to ensure efficient processes for delivery of the ebook content for scholarly activity. This involves evaluating and improving process characteristics, performance and impact.

3. Serve the participants - to meet the needs of all who participate in the e-book supply chain; those involved in using, creating and delivering e-books for academic study.

4. Create value from information - to evaluate the value of the information content of e-books and determine the best model for delivering improvements in information quality and value for scholarly activity.

5. Minimise effort absorbed by technology - to apply technology to deliver accessible, useable e-book content in a high performance system. 
6. Deploy infrastructure as a genuine resource - to use the technical, human and information resources to their greatest advantage in the e-book work system.

7. Minimise conflicts and risks - to address conflicting requirements of users and those of other participants in the e-book supply chain to reduce the risk of producing an unworkable business model of e-book delivery.

The evidence in this paper begins to address Principles 1,2, 4 and 5 by evaluating the current model of delivering academic e-books. It concludes that the current model does not please the users, perform the work efficiently, create value from information or apply technology to minimise the effort required to deliver and use e-books for academic study.

We argue that, based on our analysis of students using e-books for completion of coursework tasks, a new model for academic e-book delivery is required which meets their needs and addresses all seven of the principles in the PBSA framework.

\section{Conclusion}

This paper supports the need for development of a new model of delivering ebook content: not one that presents pages of text for scanning or reading like a printed book but a work system which meets the needs of all who use, create, license and provide e-books for academic study.

We propose the creation of a new format that pleases the user, performs processes efficiently, serves the needs of all participants in the e-supply chain (including authors, aggregators, publishers, educators and librarians), creates value from information, applies technology to minimise user effort, makes the most effective use of technical, human and information resources and minimises potential conflicts and risks. In this approach the educational context for use and the commercial infrastructure for delivery of e-books must be integral to a solution which offers accessible learning for the diverse needs of our students.

Further work is being conducted to capture the behaviour and experiences of more users (including students with a wider range of disabilities and learning needs), evaluate the issues for all those involved from creation to delivery of e-books and to develop prototypes of new e-book systems for user testing. This approach will ensure that any new system provides a viable and workable commercial solution to meeting the needs of students using e-books for scholarly activity. 


\section{References}

Alter, S. (2002) Information systems: the foundation of e-business. New Jersey: Prentice Hall. (Chapter 2).

Carden, M.T.J. (2008) E-books are not books. Conference on Information and Knowledge Management, Proceedings of the 2008 ACM workshop on research advances in large digital book repositories. California: ACM, 9-12.

Chu, H. (2003) Electronic books: viewpoints from users and potential users. Library hi tech [online], 21(3). URL: www.emeraldinsight.com/10.1108/07378830310494526 [accessed 15.10.08].

CIBER (2008) Information behaviour of the researcher of the future. London: University College London. URL:

http://www.jisc.ac.uk/whatwedo/programmes/resourcediscovery/googlegen.aspx [accessed 25.1.08].

Disability Discrimination Act (2005) c.13. URL:

http://www.opsi.gov.uk/acts/acts2005/20050013.htm [accessed 11.03.08].

JISC (2003) Promoting the uptake of e-books in Higher and Further Education, Report to JISC E-book Working Group, Gold Leaf, August 2003. URL: http://www.jisc-collections.ac.uk/workinggroups/ebooks/studies reports.aspx [accessed 26.2.08].

JISC (2008) JISC National E-books Observatory Project E-book User Survey: Findings from the first user survey. London: JISC. URL: http://www.jisccollections.ac.uk/workinggroups/ebooks/studies_reports.aspx [accessed 1.5.08].

JISC (2008a) JISC National E-books Observatory Project. . URL: http://www.jiscebooksproject.org/ [accessed 26.2.08].

JISC (2008b) Developing personalisation for the information environment . URL: http://www.jisc.ac.uk/publications/publications/personalisationfinalreport.aspx [accessed 12.10.08].

Levine-Clark, M. (2006) Electronic book usage: a survey at the University of Denver. Libraries and the Academy, 6(3), 285-299.

Marchionini, G. (1995) Information seeking in electronic environments. Cambridge University Press, Cambridge.

RIN (2007) Researchers use of academic libraries and their services. Research Information Network/Consortium of Research Libraries. URL: http://www.rin.ac.uk/researchers-use-libraries [accessed 3.2.09].

Rowlands, I. (2007) Superbook: Planning for the eBook revolution. London: University College London. URL: http://www.ucl.ac.uk/slais/research/ciber/superbook/ [accessed 25.12.08].

Rowlands, I., Nicholas, D., Hamid, R.J. and Huntington, P. (2007) What do faculty and students actually think about e-books? London: University College London. URL: http://www.homepages.ucl.ac.uk/ uczciro/findings.pdf [accessed 25.9.08]. 
Russell, M. (2008) The age of uncertainty, The Times Higher Education [online] 20 March 2008. URL:

http://www.timeshighereducation.co.uk/story.asp?storycode $=401121$ [accessed 26.05.08].

SCA (2008) Audience analysis and modelling. Strategic Content Alliance. URL: http://www.jisc.ac.uk/media/documents/themes/eresources/sca chris batt reportfi nal.pdf [accessed 3.2.09].

Scottish Executive (2008) Statistics Publication Notice: Lifelong Learning Series: Students in Higher Education at Scottish institutions 2006-07. March 2008. URL: http://www.scotland.gov.uk/Publications/2008/06/23093807/0 [accessed 26.05.08].

Snowhill, L. (2001) E-books and their future in academic libraries: an overview. D-Lib Magazine [online], 7(7/8). URL:

http://www.dlib.org/dlib/july01/07contents.html [accessed 26.2.08].

Tenopir, C. and Rowlands, I. (2007) Age-related information behaviour : Work package III. . London: University College London. URL:

http://www.ucl.ac.uk/slais/research/ciber/downloads/GG\%20Work\%20Package\% 20III.pdf [accessed 26.9.08].

Williams. P. and Rowlands, I. (2007) The literature on young people and their information behaviour: Work package II. London: University College London. URL:

http://www.ucl.ac.uk/slais/research/ciber/downloads/GG\%20Work\%20Package\% 20II.pdf [accessed 16.10.08].

Wilson, R. and Landoni, M. (2001) Evaluating electronic textbooks: a methodology. In: Proceedings of Research and Advanced technology for Digital Libraries $5^{\text {th }}$ European Conference, Darmstadt, Germany. Lecture Notes in Computer Science, 2163. Berlin, Germany: Springer. 1-12.

Wilson, R., Landoni, M. and Gibb, F. (2002) A user-centred approach to e-book design. The Electronic Library, [online] 20(4). URL:

http://www.emeraldinsight.com/Insight/ViewContentServlet?Filename=Published /EmeraldFullTextArticle/Articles/2630200406.html [accessed 12.10.08]. (Electronic Books ON-screen Interface (EBONI) Project).

\section{The Occasion}

This research was part-funded by the CILIP LIRG Research Award 2008 and was presented at the CILIP Umbrella 2009 conference at the University of Hertfordshire. 